Role of agricultural engineering in environmental and sustainable development for the valley and delta areas: 1434 - 1444

\title{
EFFECT OF STIRRING SPEED AND REACTION TIME ON SUNFLOWER BIODIESEL PRODUCTION
}

\section{H. M. S. Shoukry* and M. A. MOSALLAM** \\ ABSTRACT}

Biodiesel was produced from sunflower oil using methyl alcohol at a ratio of $22.5 \%(\mathrm{v} / \mathrm{v})$ to the oil and sodium hydroxide as a catalyst at a ratio $5.5 \mathrm{~g}$ per 1 liter oil. The production of biodiesel was carried out under four stirring speeds: 250, 500, 750 and 1000 rpm and for each stirring speed, five reaction times were used: 10, 20, 30, 40 and 50 min. the research concluded to that: 1- the optimum stirring speed for the production of biodiesel from sunflower oil is $750 \mathrm{rpm}$. 2- the optimum reaction times are 40 and $50 \mathrm{~min}$. 3- the highest biodiesel production is $98 \%$ and was obtained at $50 \mathrm{~min}$ time of reaction for each of the two speeds of stirring: 500 and $750 \mathrm{rpm}$ and at $10 \mathrm{~min}$ time of reaction under the speed $10 \mathrm{rpm}$. 5- the use of sodium hydroxide as a catalyst for the production of biodiesel from sunflower oil at a concentration of $3.5 \mathrm{~g}$ per liter of oil results in an excess soap in the produced biodiesel and a loss of biodiesel in the washing water.

\section{INTRODUCTION}

ccording to the environmental worries and the consumption of
non-renewable natural energy resources, developing alternative
resources of energy as a substitute of traditional fossil fuels has been risen. Biodiesel is among those alternatives and it is defined as an alternative fuel for diesel engines produced by chemically reacting a vegetable oil or animal fat with an alcohol, El Diwani et al. 2009. In preparation for a future petroleum fuel crisis, the United States recently made a commitment to triple bioenergy usage within 10 years. The European Union also has made a similar proposal, Barbara et al. 2008. The use of biodiesel has drawn attention in the last decade as it is a renewable, biodegradable, and nontoxic fuel, Hossain et al. 2010. The objective of this work is to study the effect of stirring speed and reaction time on the production of biodiesel from sunflower oil.

\footnotetext{
*Prof., Animal Production Dept., Fac. of Agr., Al-Azhar Univ., Cairo. ** Assoc. Prof., Agr. Eng. Dept., Fac. of Agr., Al-Azhar Univ., Cairo.
} 


\section{REVIEW OF LITERATURE}

Biodiesel is made using the process of transesterification. Transesterification is the process of using an alcohol (e.g. methanol or ethanol) in the presence of a catalyst, such as sodium or potassium hydroxide, to chemically break the molecule of the raw renewable oil into methyl or ethyl esters of the renewable oil with glycerol as a by product (Transesterification, 2000). Oil in sunflower seeds is high (40 45\%) and sunflower plant was successfully cultivated in Egypt in the new reclamined areas and in soils of salinity which does not exceed 3000 ppm and sunflower can be cultivated under different weather conditions (Kenanaonline, 2006). He et al., 2005, studied six variables which affect the production of biodiesel from canola oil using a continuousflow reactive distillation system. These variables included the feed methanol to triglycerides molar ratio, reaction time, catalyst concentration and reaction time. Singh et al. 2006, studied the production of biodiesel from canola oil at different catalyst concentrations, reaction temperatures, and methanol-to-oil molar ratios. They concluded that: the operating conditions for maximizing biodiesel yield were potassium methoxide as catalyst at $0.2 \mathrm{~mol} / \mathrm{mol}(1.59 \% \mathrm{wt})$, reaction temperature of 50.C, and methanol-to-oil molar ratio of 4.5:1. Experimental verification gave $95.8 \%$ biodiesel yield from canola oil. Dobromir et al 2007, produced biodiesel from used sunflower oil, rapeseed oil and soybean oil. The reaction was carried out under the following conditions: $60{ }^{\circ} \mathrm{C}$ reaction temperature, $1 \mathrm{~h}$ reaction time, $1-10 \% \quad(\mathrm{v} / \mathrm{v})$ sodium methoxide. The yield of biodiesel from each of the three used oils was: $85.5,86.5$ and $86 \%$ respectively. The Total Acid Number "TAN" of the produced biodiesel ranged from 0.018 to $0.024 \mathrm{mgKOH} / \mathrm{g}$. Barbara $\boldsymbol{e t}$ al. 2008, used a mixtures of commercial oils for the production of biodiesel. The reactions were carried out under stirring speeds of 600 $\mathrm{rpm}$, time of reaction of $30 \mathrm{~min}$, temperature of $65{ }^{\circ} \mathrm{C}$, catalyst (lithium hydroxide) of ratio $1.5 \%(\mathrm{w} / \mathrm{w})$ and methanol to oil molar ratio of 3: 1 . The mixture of the oils: corn, cotton, sunflower, canola and coconut gave $97.89 \%$ (w/w) biodiesel yield. El Diwani et al. 2009, produced biodiesel from jatropha oil under bench and pilot scales. They used methyl alcohol at ratio $10 \%$ by volume to the oil and sodium hydroxide as a catalyst at 
ratio $1 \%$ by weight to the oil. The reaction was carried out under temperature of $65{ }^{\circ} \mathrm{C}$ for one hour. Percent of the produced biodiesel was $98 \%$. "TAN" for the biodiesl produced under bench and pilot scales were: 0.26 and $0.30 \mathrm{mgKOH} / \mathrm{g}$ respectively and the Calorific Values "C.V." were 40.59 and $39.44 \mathrm{Mj} / \mathrm{kg}$. Hossain et al. 2010, produced biodiesel from waste canola oil. Conditions of the reaction were: 1: 1 molar ratio of methanol to oil, temperature of reaction of $55{ }^{\circ} \mathrm{C}$, stirring speed of $250 \mathrm{rpm}$, time of reaction of $2 \mathrm{~h}$ and $0.5 \%$ sodium hydroxide. The yield of biodiesel was $49.5 \%$ and TAN was $0.1 \mathrm{mgKOH} / \mathrm{g}$. Math $\boldsymbol{e t}$ al. 2010, produced biodiesel from a mixture of $75 \%$ restaurant waste oil and $25 \%$ pig fat oil. They got $80 \%(\mathrm{v} / \mathrm{v})$ yield of biodiesel. They mentioned that the optimum conditions for the reaction are: methanol percent of $40 \%(\mathrm{v} / \mathrm{v})$, temperature of $65^{\circ} \mathrm{C}$, time of reaction of $90 \mathrm{~min}$, sodium hydroxide of $0.3 \%(\mathrm{w} / \mathrm{w})$ and $1.5 \mathrm{~cm}^{3}$ sulfuric acid. Hamed $\boldsymbol{e t}$ al. 2006, produced biodiesel from Salmon oil. They used sulfuric acid to reduce the acid value of the salmon oil from 12.04 to $3 \mathrm{mg} \mathrm{KOH} / \mathrm{g}$. the reaction carried out under a temperature of $52^{\circ} \mathrm{C}$ and $600 \mathrm{rpm}$ stirring speed. Biodiesel yield was $99 \%(\mathrm{w} / \mathrm{w})$ under methanol molar ratio of 9.2 and sodium hydroxide of $0.5 \%(\mathrm{w} / \mathrm{w})$. To compare the effect of stirring speed of $1800 \mathrm{rpm}$ with respect to ultrasonic irradiation in the production of biodiesel from triolein, Hoang et al. (2007) obtained 93\% yield under $25^{\circ} \mathrm{C}$ temperature, molar ratio of ethanol/triolein of $6 / 1$, base catalyst concenteration of $1 \mathrm{wt} \%$ for both $\mathrm{NaOH}$ and $\mathrm{KOH}$ and reaction time of of less than $20 \mathrm{~min}$.

\section{MATERIALS AND METHODS}

A commercial sunflower oil (Slite trade) was used in these experiments. Methanol alcohol (99.8 concentration) was used for the production of biodiesel. The alcohol was used at a ratio, by volume, $22.5 \%$ to the oil. Sodium hydroxide was used as a catalyst for the production of biodiesel at a ratio of $5.5 \mathrm{~g}$ per 1 liter oil (in preliminary experiments, a concentration of $3.5 \mathrm{~g}$ of sodium hydroxide per each liter of oil and 27.5 $\%$ by volume methanol alcohol to the oil, were tested for the production of biodiesel. The produced biodiesl has an excess quantity of soap and needed to be washed for more than 10 times and a noticeable quantity of the biodiesel drained out with the washing water - the produced biodiesel 
according to the previously mentioned concentrations, for the preliminary experiments, was analyzed for the Total Acid Number "TAN" and the Calorific Value "C.V."). An overhead mechanical stirrer (Wheaton instrument trade) of power of $120 \mathrm{~W}$ was used for the reaction. The stirrer has a speed range from 0 to $15000 \mathrm{rpm}$. The stirrer was adjusted to the required reaction stirring speed using a tachometer: Cole Parmer trade, Model 8203 - 10. biodiesel was produced under four stirring speeds: 250, 500, 750 and $1000 \mathrm{rpm}$. For each speed, five times of reaction were investigated. These times are: 10, 20, 30, 40 and $50 \mathrm{rpm}$ (the choosed values of stirring speeds and reaction times are based on Preliminary experiments).

Steps of production of biodiesel were as follows: sodium hydroxide was dissolved in the methanol alcohol to form the sodiummethoxide using the stirrer. For each time under each tested speed, two replicates were tested. For each replicate, $200 \mathrm{~cm}^{3}$ oil was added to $45 \mathrm{~cm}^{3}$ sodiummethoxide and the mixture was stirred to perform the transesterification process. Then the sample was transferred into a $250 \mathrm{~cm}^{3}$ measuring cylinder and left for separation for $3 \mathrm{~h}$ or more. The sample separates into two layers: the lower one which is glycerin and the upper one which is methyl ester of the sun flower oil (which includes soap, alcohol, impurities, etc). using a pipette, half of the produced methyl ester was transferred into a 250 $\mathrm{cm}^{3}$ separating funnel. $25 \mathrm{~cm}^{3}$ of distilled water was added into the funnel, then the funnel was shaked to mix the water and the ester. The sample was left for the separation of the washing water. After separation of the washing water, the water was drained out of the funnel and the washing process was repeated (5 - 7 times) till the washing water became clear. The washed biodiesel was then transferred into a $250 \mathrm{~cm}^{3}$ measuring cylinder to determine its volume. The determined biodiesl volume was calculated as a percent, by volume with respect to the half of the volume of the oil used in the sample $\left(100 \mathrm{~cm}^{3}\right)$. The produced biodiesel was analyzed for the Total Acid Number "TAN" and the Calorific Value "C.V." at the Egyptian Petroleum Research Institute. Also the produced biodiesel was tested for cleanliness according to Daniel, 2010 : $3 \mathrm{~cm}^{3}$ of the produced washed biodiesel were dissolved into $27 \mathrm{~cm}^{3}$ methanol alcohol to note if there exists undissolved liquids or suspended impurities. 


\section{RESULTS AND DISCUSSION}

Table (1) shows the produced biodiesel at each of the five tested times of reaction (10, 20, 30, 40 and $50 \mathrm{~min}$ ) for each of the four tested stirring speeds ( 250, 500, 750 and $1000 \mathrm{rpm}$ ). Fig. (1) shows the relation between biodiesel production and time of reaction at each of the four tested stirring speeds.

Table (1): The produced biodiesel at each of the five tested times of reaction for each of the four tested stirring speeds.

\begin{tabular}{|c|c|c|c|c|}
\hline \multirow{2}{*}{ Time (min) } & \multicolumn{4}{|c|}{ Stirring speed (rpm) } \\
\cline { 2 - 5 } & $\mathbf{2 5 0}$ & $\mathbf{5 0 0}$ & $\mathbf{7 5 0}$ & $\mathbf{1 0 0 0}$ \\
\cline { 2 - 5 } & \multicolumn{4}{|c|}{ Biodiesel production (\% by volume) } \\
\hline 10 & $\mathbf{5 0}$ & $\mathbf{7 0}$ & $\mathbf{8 6}$ & $\mathbf{9 8}$ \\
\hline 20 & $\mathbf{8 5}$ & 90 & 96 & 92 \\
\hline 30 & 93 & 95 & 96 & 92 \\
\hline 40 & 95 & 95 & 96 & 92 \\
\hline 50 & 96 & 98 & 98 & 90 \\
\hline
\end{tabular}

Table (1) and Fig. (1) show that:

1- For stirring speeds 250, 500 and $750 \mathrm{rpm}$, the production of biodiesel increases as the time of reaction increase.

2- For these three speeds, the production of biodiesel becomes nearer and at its utmost range ( $95-98 \%$ ) at the times 40 and $50 \mathrm{~min}$.

3- For the speed $100 \mathrm{rpm}$, the biodiesel production decreases as the time increase.

4- The highest biodiesel production recorded is $98 \%$ and occurs at 50 min for each of the speeds 500 and $750 \mathrm{rpm}$ and at $10 \mathrm{~min}$ for the speed $1000 \mathrm{rpm}$.

5- The lowest biodiesel production (50\%) is obtained at $10 \mathrm{~min}$ for the speed $250 \mathrm{rpm}$.

Fig. (2) shows the relation between biodiesel production and stirring speed at each of the five tested times of reaction. Table (1) and Fig. (2) show that:

1- For times of reaction: 20, 30, 40 and $50 \mathrm{~min}$, the production of biodiesel increases as the speed of stirring increase till the speed $750 \mathrm{rpm}$ Where the production begins to decrease. Speed $750 \mathrm{rpm}$ is considered to be the optimum speed for producing biodiesel from sunflower oil. 
2- At 10 min time of reaction, the production of biodiesel increases considerably as the speed of reaction increase.

Table (2) shows analysis of a sample of the produced biodiesel for the "TAN" and the "C.V." according to the Egyptian Petroleum Research Institute:

Table (2): Analysis of the produced biodiesel:

\begin{tabular}{|c|c|}
\hline $\begin{array}{c}\text { Calorific Value (cal/gm) } \\
\text { ASTM D 240 }\end{array}$ & $\begin{array}{c}\text { Total acid number }(\mathrm{mgKOH} / \mathrm{g}) \\
\text { ASTM D 664 }\end{array}$ \\
\hline 9855.79 & 0.272 \\
\hline
\end{tabular}

When dissolving $3 \mathrm{~cm}^{3}$ of the produced biodiesel in $27 \mathrm{~cm}^{3}$ of methanol alcohl (test of cleanliness according to Daniel, 2010), the biodiesel dissolved at once completely in the alcohol and no impurities were left. Table (3) shows the biodiesel produced in a preliminary experiment (at a concentration of $3.5 \mathrm{~g}$ of sodium hydroxide per each liter of oil and 27.5 $\%$ by volume methanol alcohol to the oil) under the four tested speeds at the corresponding given times of reaction:

Table (3): The produced biodiesel using sodium hydroxide at $3.5 \mathrm{~g}$ per liter oil.

\begin{tabular}{|c|c|c|c|c|}
\hline \multirow{2}{*}{ Time (min) } & \multicolumn{4}{|c|}{ Stirring speed (rpm) } \\
\cline { 2 - 5 } & $\mathbf{2 5 0}$ & 500 & $\mathbf{7 5 0}$ & 1000 \\
\cline { 2 - 5 } & \multicolumn{3}{|c|}{ Biodiesel production (\% by volume) } \\
\hline 10 & ---- & ----- & ----- & 68 \\
\hline 20 & ---- & 42 & 64 & ---- \\
\hline 30 & 26 & ----- & ----- & 28 \\
\hline 40 & ---- & ---- & ---- & ---- \\
\hline 50 & ----- & 60 & ---- & ---- \\
\hline
\end{tabular}

This produced biodiesel was analysed for the "TAN" and the "C.V." at the Egyptian Petroleum Research Institute. The analysis was according to table (4):

Table (4): Analysis of the produced biodiesel using sodium hydroxide at $3.5 \mathrm{~g}$ per liter oil.

\begin{tabular}{|c|c|}
\hline $\begin{array}{c}\text { Calorific Value (cal/gm) } \\
\text { ASTM D 240 }\end{array}$ & $\begin{array}{c}\text { Total acid number }(\mathrm{mgKOH} / \mathrm{g}) \\
\text { ASTM D 664 }\end{array}$ \\
\hline 8883.73 & 0.113 \\
\hline
\end{tabular}




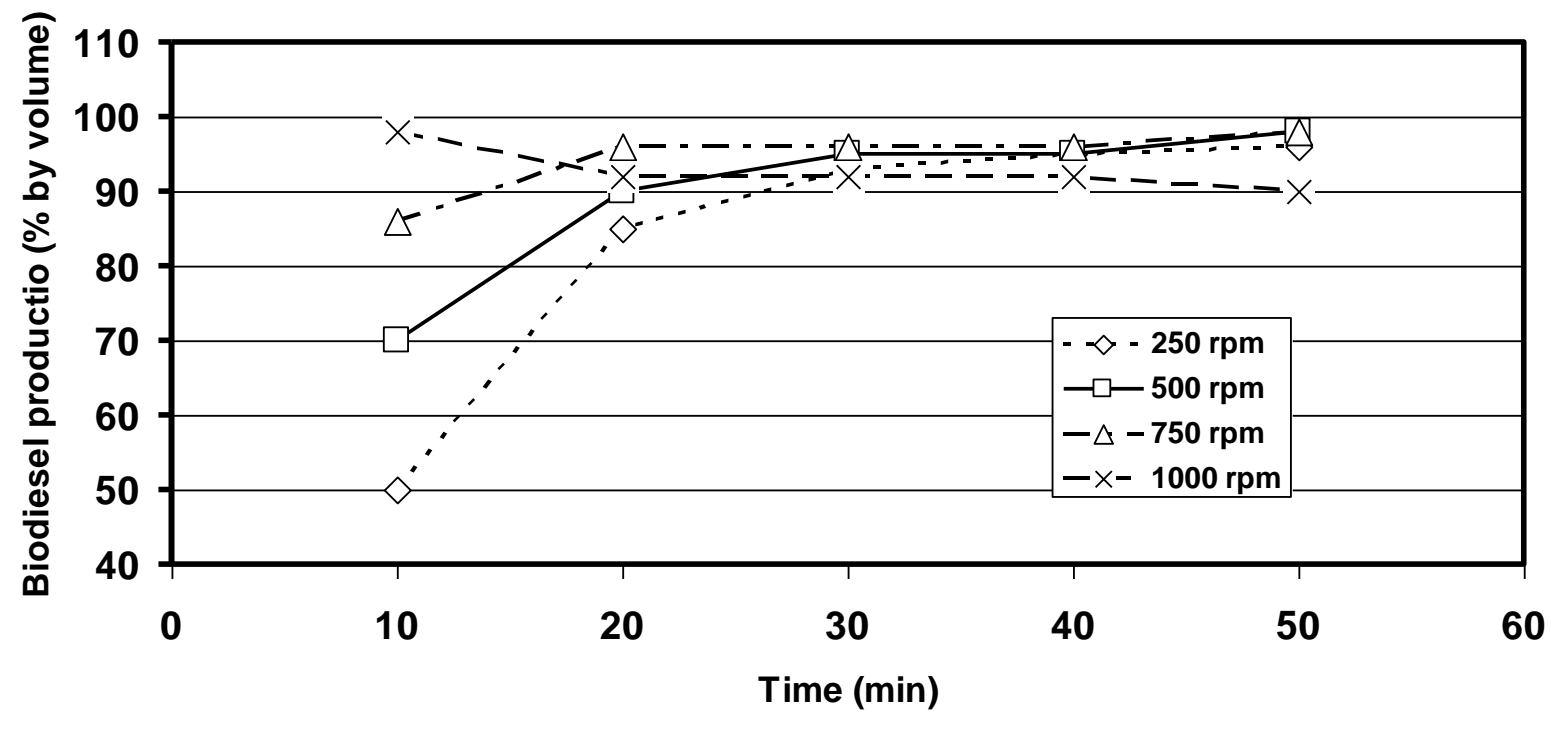

Fig. (1): The relationship between biodiesel production (\% by volume) and time (min) at each of the four tested stirring speeds. 


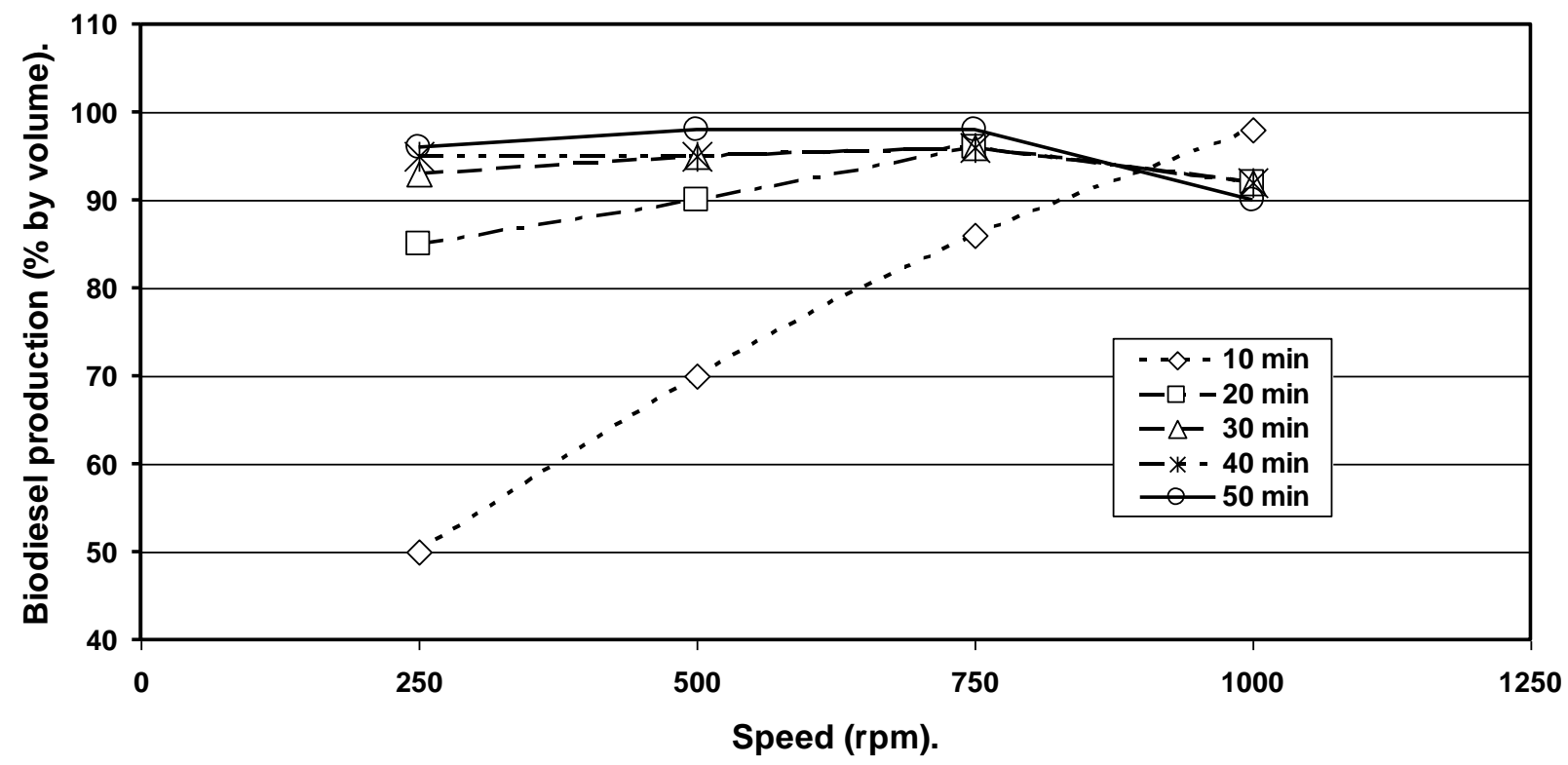

Fig. (2): The Relationship between between biodiesel poduction (\% by volume) and stirring speed (rpm) at the tested five times. 


\section{SUMMARY}

Commercial sunflower oil (Slite trade) was used for the production of biodiesel. For the formation of the oil ester ( the biodiesel), the methyl alcohol was used at a ratio of $22.5 \%(\mathrm{v} / \mathrm{v})$ to the oil and sodium hydroxide was used as a catalyst for the production of the methyl ester of the oil at a ratio $5.5 \mathrm{~g}$ per 1 liter oil.

A mechanical stirrer was used for the production of the methyl ester of the oil. The production of biodiesel was carried out under four stirring speeds: 250, 500, 750 and $1000 \mathrm{rpm}$ and for each stirring speed, five reaction times were used: 10, 20, 30, 40 and $50 \mathrm{~min}$.

The produced biodiesel was analysed for the total acid number and the calorific value at the Egyptian Petroleum Research Institute.

Research results showed the following:

1- The optimum stirring speed for the production of biodiesel from sunflower oil is $750 \mathrm{rpm}$.

2- The optimum reaction times are 40 and $50 \mathrm{~min}$.

3- The highest biodiesel production is $98 \%$ and was obtained at $50 \mathrm{~min}$ time of reaction for each of the two speeds of stirring: 500 and $750 \mathrm{rpm}$ and at 10 min time of reaction under the speed $10 \mathrm{rpm}$.

4- The Calorific Value of the produced biodiesel is 9855.79 and the total acid number is $0.272 \mathrm{mgKOH} / \mathrm{g}$.

5- The use of sodium hydroxide as a catalyst for the production of biodiesel from sunflower oil at a concentration of $3.5 \mathrm{~g}$ per liter of oil results in an excess soap in the produced biodiesel and a loss of biodiesel in the washing water.

\section{REFERANCES}

Bárbara A., B. Facio, A. Jiménez, E. Rogel- Hernández, and H. Espinoza- Gómez (2008). The Production of Biodiesel from Blended Commercial Oil in Mexico: A Comparative Study. Facultad de Ciencias Químicas e Ingeniería. Universidad Autónoma de Baja California. Calzada Tecnológico 14418, C.P. 22340

Daniel B. (2010). AGR Energy, www. Agrenergy.com. Accessed on July, 2010. 
Dobromir I. J., P. S. Petkov, Y. K. Dimitrov and S. K. Ivanov (2007). METHANOL TRANSESTERIFICATION OF DIFFERENT VEGETABLE OILS. Petroleum \& Coal 49 (2), 21-23, 2007

El Diwani G., N. K. Attia, S. I. Hawash (2009). Development and evaluation of biodiesel fuel and by-products from jatropha oil. Int. J. Environ. Sci. Tech., 6 (2), 219-224, Spring 2009

Hossain A. B. M. S., A. N. Boyce, A. Salleh and S. Chandran (2010). Impacts of alcohol type, ratio and stirring time on the biodiesel production from waste canola oil. African Journal of Agricultural Research Vol. 5(14), : 1851-1859

Hoang D. H., N. T. Dong., K. Okitus, Y. Maeda and R. Nishimura. Effects of molar ratio (2007), Catalyst concentration and temperature on transesterification of triolein with ethanol under ultrasonic irradiation. Japan Petroleum Institute, 5. (4): 195-199

Hamed M. El-Hashed, R. Zhang, R. J. Avena-Bustillos (2006). Biodiesel production rom Fish oil. Paper number 066144, ASAE Annual M.tg.

He B. B., A. P. Singh, J. C. Thompson (2005). Experimental optimization of a continuous-flow reactive distillation reactor for biodiesel production.. Transactions of the ASABE. Vol. 48(6): 2237-2243

Kenana.com (2006). Accessed on July 2010.

Math M. C, Sudheer Prem Kumar and Soma V. Chetty (2010). Optimization of biodiesel production from oils and fats with high free fatty acids. Indian Journal of Science and Tec. Vol. 3 No. 3 (Mar 2010) ISSN: 0974- 6846 Research article.

Singh A., B. He, J. Thompson, J. Van Gerpen (2006). Process optimization of biodiesel production using alkaline catalysts. Applied Engineering in Agriculture. Vol. 22(4): 597-600

Transesterification (2000). Turning used vegetable oil into clean burning biodiesel fuel. (http://www.vegievan.org/transest.html). Accessed on July 2010. 


\section{الملخص العربي

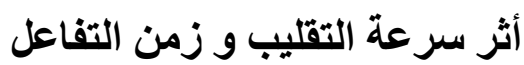

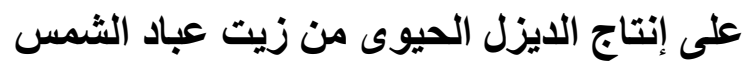

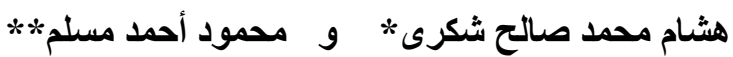

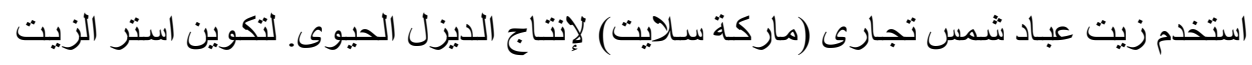

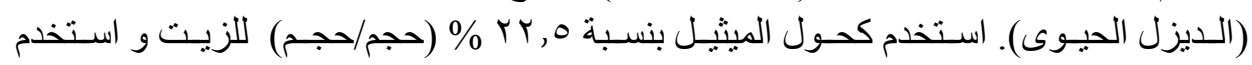

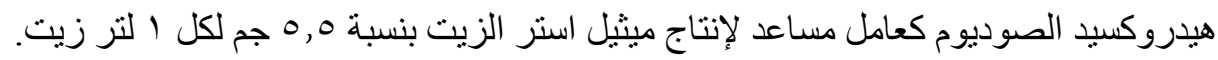

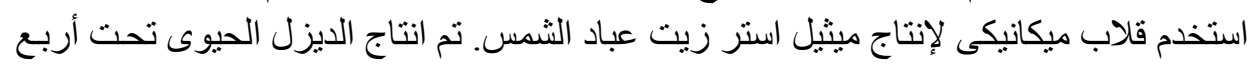

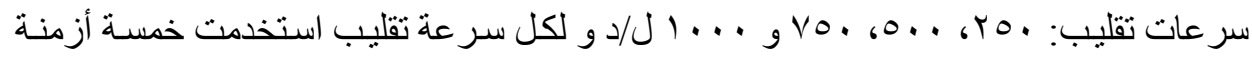

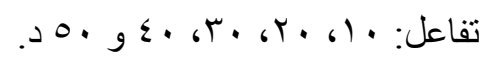
تم تحليل الديزل الحيوى النـاتج لرقم الأحمـاض الكلى و للقيمـة الحر اريـة بمعهد بحوث البترول

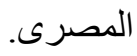

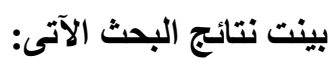

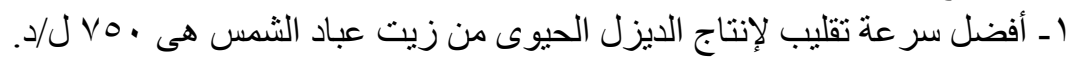

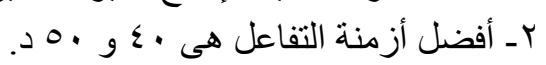

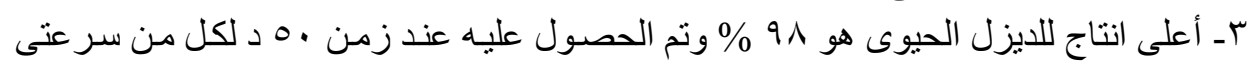

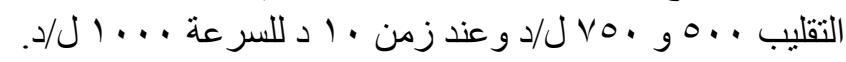

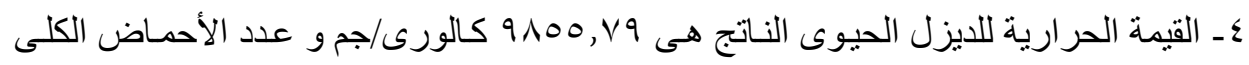

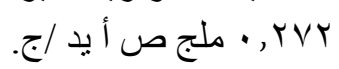

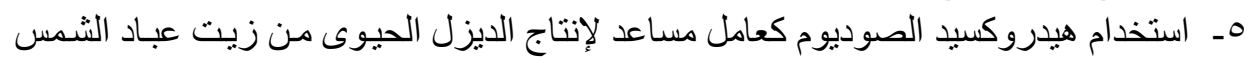

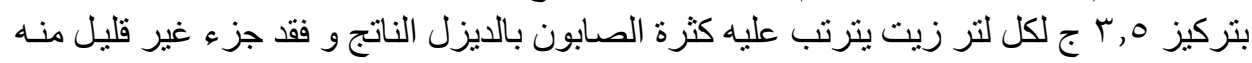

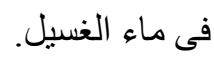

\footnotetext{
* أستاذ - قسم الإنتاج الحيو انى - كلية الزراعة ـ - جامعة الأزهر - القاهرة.

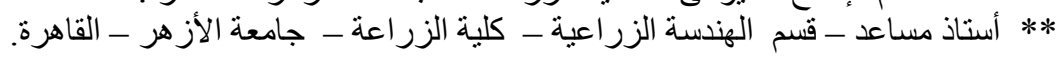

